\title{
RESEARCH
}

Open Access

\section{Nationwide survey of neonatal transportation practices in Italy}

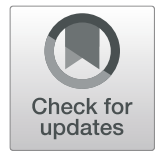

Maurizio Gente ${ }^{1}$, Roberto Aufieri ${ }^{2}$, Rocco Agostino ${ }^{3}$, Tiziana Fedeli ${ }^{4}$, Maria Grazia Calevo ${ }^{5}$, Paolo Massirio ${ }^{6}$, Carlo Bellini ${ }^{6^{*}}$ (D) and on behalf of the Neonatal Transport Study Group of the Italian Society of Neonatology (SIN)

\begin{abstract}
Background: Despite regionalization of perinatal care provides for the "in utero" transfer of high-risk pregnancies, there will always be a number of neonates who undergo acute inter-facility transport. The presence of a well-organized Neonatal Emergency Transport Service (NETS) can prevent and reduce risks of transportation, especially for very preterm infants, and is therefore mandatory for any program of regionalization of perinatal care. Italian National Health System is highly decentralized and Regions are autonomous to structure, plan and delivery their regional health services. Consequently, organization models and resources available vary widely and significant regional differences in access and quality of health services have been reported in the past years. A national survey was conducted in 2015 by the neonatal transport study group of the Italian Society of Neonatology with the aim to describe neonatal transfer practices and to assess the Neonatal Emergency Transport Services (NETS) status in the 20 Italian regions.
\end{abstract}

Methods: A questionnaire regarding neonatal transfer practices and NETS activity for the previous year (2014) was sent to the 44 NETS operating in the 20 Italian regions. Demographic data were obtained from the Italian National Statistical Institute (ISTAT).

Results: The overall survey response rate was 100\%. In 2014, only 12 (60\%) of the 20 Italian regions were fully covered by NETS, 3 (15\%) regions were partially covered, while neonatal transport was not available in 5 (25\%) regions. Overall, in 2014, the 44 NETS operating in Italy transported a total of 6387 infants, including 522 (8.17\%) having a gestational age $<28$ weeks.

Conclusions: The organization of NETS in Italy is devolved on a regional basis, resulting in a large heterogeneity of access and quality to services across the country. Where available, NETS are generally well-equipped and organized but limited volume of activities often cannot guarantee adequate levels of skills of personnel or an appropriate cost-efficiency ratio. The regions reported with lack of NETS have managed, or are trying, to fill the gap, but continuing efforts to reduce regional differences in the availability and quality of services are still needed.

Keywords: Infant, newborn, Intensive care, neonatal transport, Perinatal care, Regional medical programs, Health services accessibility

\footnotetext{
* Correspondence: carlobellini@gaslini.org

${ }^{6}$ Neonatal Intensive Care Unit, Neonatal Emergency Transport Service,

Department Mother\&Child, IRCCS Istituto Giannina Gaslini, Largo G. Gaslini, 5,

16147 Genoa, Italy

Full list of author information is available at the end of the article
}

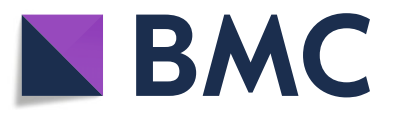

C The Author(s). 2019 Open Access This article is distributed under the terms of the Creative Commons Attribution 4.0 International License (http://creativecommons.org/licenses/by/4.0/), which permits unrestricted use, distribution, and reproduction in any medium, provided you give appropriate credit to the original author(s) and the source, provide a link to the Creative Commons license, and indicate if changes were made. The Creative Commons Public Domain Dedication waiver (http://creativecommons.org/publicdomain/zero/1.0/) applies to the data made available in this article, unless otherwise stated. 


\section{Background}

In a network aimed at the regionalization of perinatal care, high-risk pregnancies should be transferred "in utero" in order to minimize risks to both the mother and the neonate $[1,2]$. However, it is not always feasible to predict and prevent all the conditions possibly requiring neonatal care that cannot be provided in the referral center and there will always be a number of neonates who undergo acute inter-facility transport [3]. Neonatal transport represents an additional risk factor for a critically ill patient, especially for very preterm infants $[1,4]$. Therefore, the presence of a well-organized Neonatal Emergency Transport Service (NETS) is mandatory for a perinatal regional network, as it represents the link between birth centers and neonatal intensive care units (NICUs) and can reduce risks of transportation, especially for very preterm infants $[5,6]$. In the past years, a program of regionalization of perinatal care was implemented and NETS have been progressively activated in Italy $[7,8]$.

Regional governments in Italy have the autonomy to legislate issues regarding healthcare, thus resulting in regional variations in resources and models of organizations with differences in health care quality and outcomes, as measured by several indicators and reported by the Organisation for Economic Co-operation and Development (OECD) and the European Observatory on Health Systems and Policies $[9,10]$.

The aim of this study was to describe neonatal transfer practices and to assess the current organization of NETS in Italy. For this purpose, in 2015, a national survey was carried out by the neonatal transport study group of the Italian Society of Neonatology (SIN) under the auspices of the Italian Ministry of Health.

\section{Methods}

\section{Survey}

A survey regarding NETS activity was conducted in 2015, at all 44 existing Italian NETS. An exploratory, descriptive design, including a survey questionnaire, was adopted to maximize sample size and facilitate data collection. A multiple-choice questionnaire consisting of 20 questions regarding NETS organization and activity data for the previous year (2014) was designed by the SIN neonatal transport study group. The aim of the questionnaire was mainly to identify and describe NETS status, organization, coverage and activity; therefore, questions regarding outcomes of the transferred newborns were not included in this survey.

The questionnaire included questions about: a) annual volume of NETS activity, including the number of primary and back transports, number of transported newborns $\leq 28$ week gestational age (GA), number of transports of infants over 28 days of life or 44 weeks of corrected GA for preterm infants, and average time of each transport; b) type of organization (i.e., number of unit-based teams, dedicated teams, and free-standing independent transport services); c) policies for quality evaluation, training and education d) vehicles used, including the availability of a helicopter for air transports.

The survey received approval from the SIN institutional review committee. The web-based survey tool Survey Monkey (http://www.surveymonkey.com/) was used and emails were sent to the person in charge of the NETS at each institution asking them to participate in the survey and to fill in the online questionnaire. Filling in the questionnaire implied consent to participate.

Filled in questionnaires were checked for invalid responses or missing data. Requests for missing information were made to the NETS directors by the secretary of the SIN Neonatal Transport study group by telephone. When all the questionnaires were ready the data were transferred to an electronic database and evaluated by the SIN neonatal transport study group.

Demographic data were obtained from governmental sources (ISTAT, Istituto Nazionale di Statistica - National Statistical Institute, available at http://www.istat.it/ ). Data about the number of birth centers and the number of birth centers with less than 500 births/year operating in 2014 were obtained, for each region, by the document of the Italian Ministry of Health: "Attuazione delle azioni previste dall'accordo del 16 dicembre 2010. Linee di indirizzo per la promozione e miglioramento della qualità, della sicurezza e dell'appropriatezza degli interventi assistenziali nel percorso nascita e per la riduzione del taglio cesareo. Monitoraggio al 31 dicembre 2014", with the exception of Lazio and Campania, where data obtained from the available regional reports have been used [11-13].

\section{Italian administrative organization}

Italy is subdivided into 20 regions, five of which have a special autonomous status. The Italian State has run a universal public national healthcare system since 1978, which is managed by the Ministry of Health and administered on a devolved regional basis. Each regional government is responsible for organizing its own healthcare system. The results were grouped by region to allow a comparison among regions and not among individual NETS.

\section{Statistical analysis}

Statistical analysis consisted of descriptive statistics and the evaluation of categorical variables; continuous variables are presented as mean values \pm standard deviation (SD), whereas they are presented as absolute and relative frequencies where needed. Data are provided both as absolute numbers and relative frequencies. The $\chi^{2}$ test or 
Fisher's exact test were used to compare differences in categorical variables between groups. A $p$-value less than 0.05 was considered statistically significant, and all $p$-values were based on two-tailed tests. Statistical analysis was performed using SPSS for Windows (SPSS, Inc., Chicago, IL).

\section{Results}

The response rate for the questionnaire was 100\% (44/44). After a single request for missing data the 44 questionnaires were fully filled in, thus all of them were included in the analysis. The results, including demographic data for each region, are reported in Table 1.

\section{Regional coverage}

Results showed that in 2014, among the 20 Italian regions only 12 were fully covered by NETS (Piemonte, Lombardia, Trentino-Alto Adige, Veneto, Friuli-Venezia Giulia, Liguria, Toscana, Marche, Lazio, Molise, Campania, and Basilicata), 3 regions (Emilia-Romagna, Puglia e Sicilia) were partially covered, while neonatal transport was not available in 5 regions (Valle d'Aosta, Umbria, Abruzzo, Calabria e Sardegna) (Fig. 1, panel a).

\section{NETS organization}

The results of the survey showed how all 44 NETS guaranteed 24/7 service coverage. 41/44 NETS were organized as an on-call service, while three were fully dedicated services. Each of the forty-one on-call NETS was linked to a NICU which provided a senior neonatologist and a neonatal nurse for each transport.

\section{NETS activity}

Overall, in 2014, the 44 NETS in Italy transported a total of 6387 infants, $522(8.17 \%)$ of whom were of GA $<28$ weeks, and 635 (9.94\%) who were back-transported infants. Median regional transport time was $123 \mathrm{~min}$ (minimum-maximum range 60-190).

Among the 41 on-call NETS, 3 carried out fewer than 20 transports per year, 7 carried out between 21 and 40, 10 between 41 and 80, 6 between 81 and 100, a further 10 between 101 and 200 and only 5 on-call NETS carried out more than 200 transports per year. All the 3 dedicated services carried out more than 200 transports per year (Fig. 1, panel b). The number of total transports and back-transports varied widely within the Italian territory (Fig. 2).

21/ 44 NETS also provided transportation for infants and children older than 28 days of life or 44 weeks of corrected GA for preterm. These patients were transferred both from the same hospitals where the services were based (9\% from the NICUs, 23\% from other units) and from other hospitals (68\% of cases). T Most of them weighed less than $6 \mathrm{~kg}(67 \%)$ and in $48 \%$ of cases were infants below 3 months of age. However, 14\% of these transports involved children weighing more than $10 \mathrm{~kg}$ and who were over 1 year of age.

The neonatal transport index (NTI) i.e., the number of neonates transferred per 100 live births (back-transports included or excluded), is reported in Table 1. We performed a broad statistical analysis and found that the comparison between the maternity wards per NETS ratio vs NTI for primary transports and the comparison between the rate of hospitals with $\leq 500$ births per year vs 30 -day mortality was significant ( $p$-value $<0.00001$ and 0.00002 , respectively) while the comparison between the number of neonatal transports vs 30-day mortality was slightly significant ( $\mathrm{p}$-value 0.007$)$. No other statistically significant results were observed.

\section{Vehicles and air transport}

Dedicated ambulances for neonatal transport were owned by 23/44 NETS (52.2\%). Fifteen of the 21 NETS based at a level III NICU, where a dedicated ambulance for neonatal transport was not available, reported that they were unable to purchase one owing to financial constraints.

Air transport by helicopter was not available for all NETS, as it was only carried out in 10 of the 15 regions covered by NETS. Fixed wing air transport was not available on a routine basis all over Italy. However, the Italian Air Force allowed NETS to use their aircraft for urgent cases, mainly for transfers of neonates with congenital heart defects or surgical emergencies.. This occurred especially for transports from the islands of Sicilia and Sardegna towards cities with hospitals providing pediatric/neonatal surgery, cardiothoracic surgery or other special care.

\section{Quality evaluation, training and education}

A dedicated NETS database was available in $42 / 44$ services; specific guidelines were edited by $43 / 44$ NETS and in one case by the "112 Emergency Service" (118 at the time of the Survey), (i.e., 911 in the USA and 999 in the UK). Regular auditing was performed by $36 / 44$ NETS; in two services through an agreement with the "112 Emergency Services". No auditing was performed on a regular basis by the remaining 8 NETS. Training and education activities were provided at 40/44 NETS, at 2 NICUs linked to NETS, and at one 112 Emergency Service.

\section{Discussion}

Organized NETS activity in Italy became available during the eighties [14], but it was during the nineties that NETS coverage mainly spread throughout Italy, with 10 of the 20 Italian regions reaching regional coverage $>50 \%$ in 1999 [9]. The agreement of the State-Regions Conference in December 2010 (also known as "birth path" or "percorso 


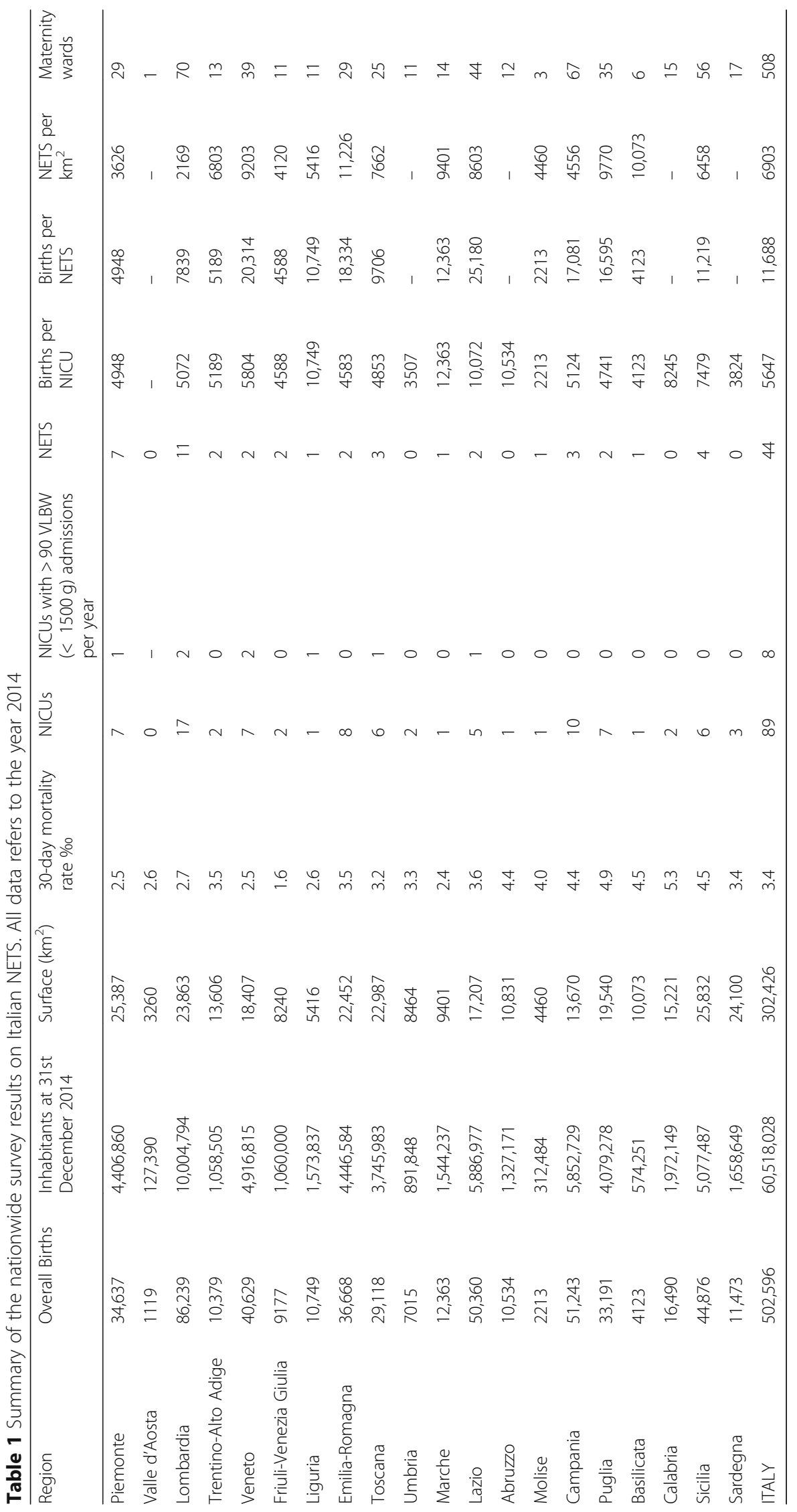




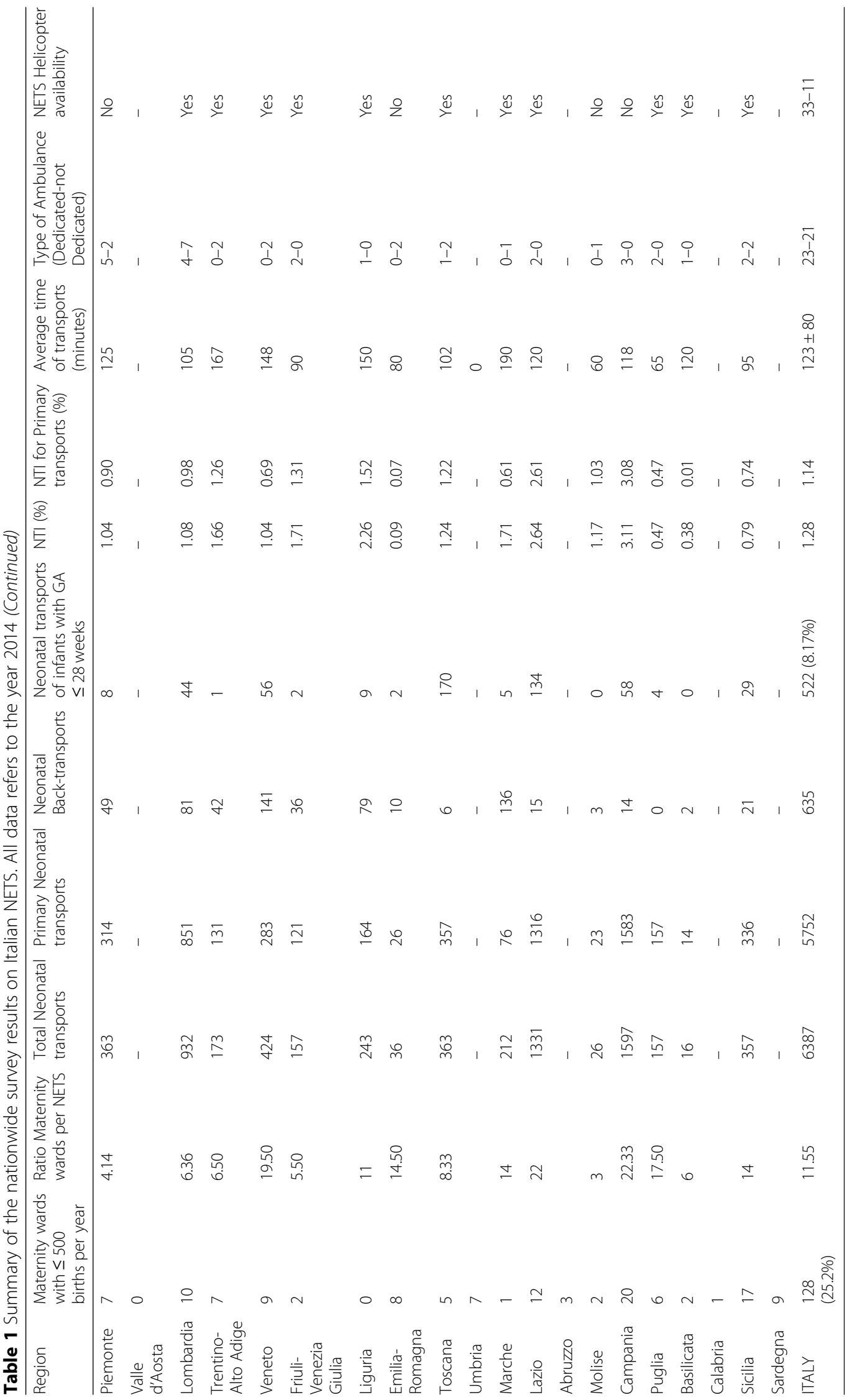




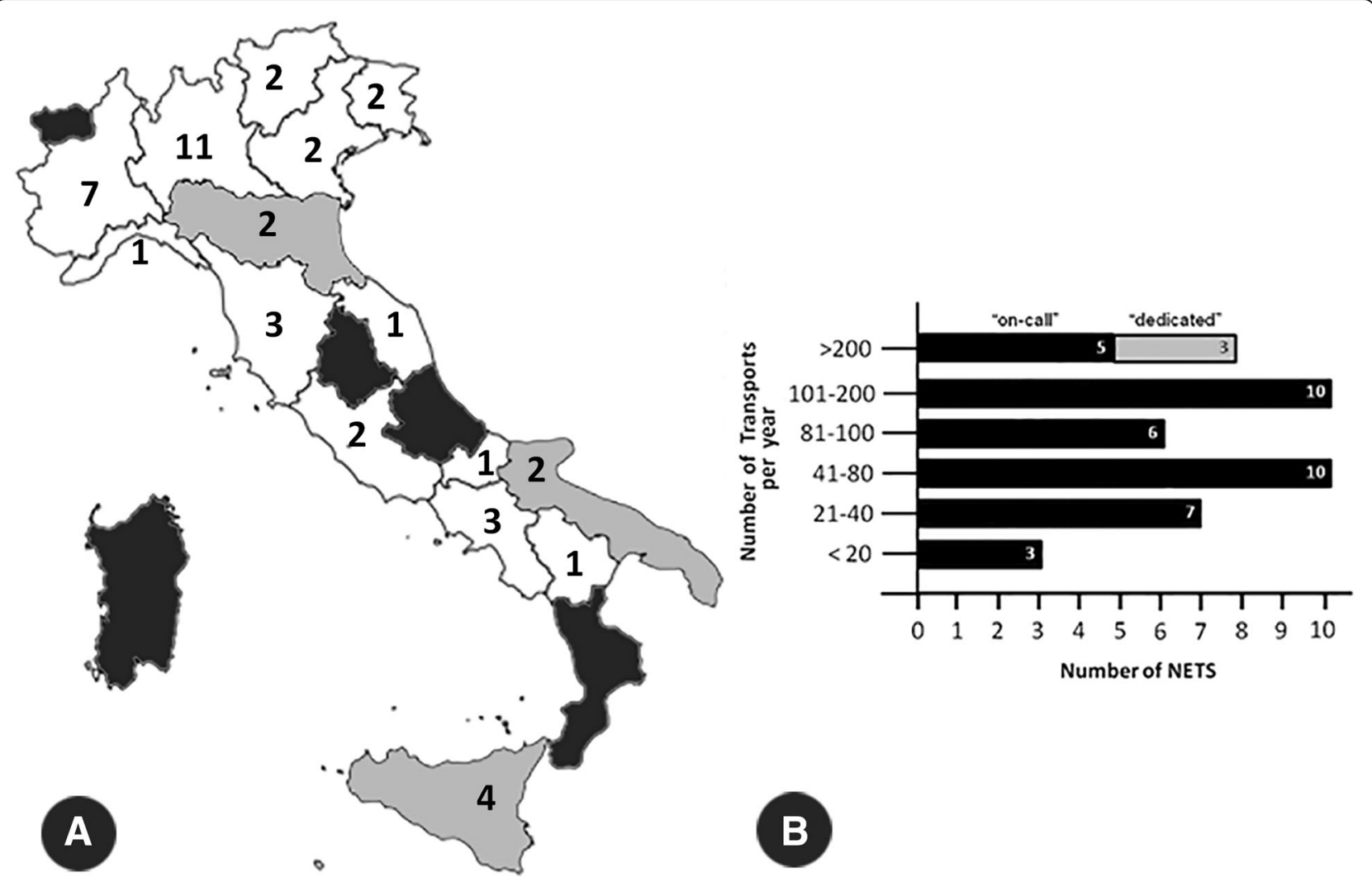

Fig. 1 Geographical distribution and amount of activity of the 44 Italian NETS. Panel a. Geographical distribution of NETS in Italy, in 2014. Regional borders are shown. White regions were fully covered by NETS (Piemonte, Lombardia, Trentino-Alto Adige, Veneto, Friuli-Venezia Giulia, Liguria, Toscana, Marche, Lazio, Molise, Campania, and Basilicata); grey regions were partially covered (Emilia-Romagna, Puglia e Sicilia); NETS was not available in black regions (Valle d'Aosta, Umbria, Abruzzo, Calabria e Sardegna). Panel b. Number of transports per year of the 44 NETS, in 2014. All the three NETS organized on a dedicated model carried out more than 200 transports per year

nascita") provided guidance to standardize pregnancy and childbirth practices at regional level, including the adoption of perinatal networks based on the "hub and spoke" organizational model that guarantee the presence of Maternal and Neonatal Emergency Transport Services [15]. However, our study shows how in 2014 neonatal transport was still not available in an organized form in five Italian regions, though a NETS is not strictly required in Valle d'Aosta since there is only one perinatal center in that region.

The NTI is considered an indicator of the quality of regionalization of perinatal care [16]. In countries where perinatal care is highly regionalized, like in the UK, the NTI can be as low as $1 \%[17,18]$. Whereas in the past, in areas with heterogeneous distribution of obstetrics units, the NTI reached values of about $10 \%$, e.g., in the Loire-Atlantique region in France [18] or in Portugal [19]. Our survey showed that regions which were fully covered by NETS, in 2014, had a mean NTI for primary transports (back-transports excluded) of $1.27 \pm 0.84$ and that the three other regions with partial NETS coverage had a mean NTI for primary transports of $0.43 \pm 0.34$.
The two regions with the highest NTI for primary transports were Campania (NTI 3.08) and Lazio (NTI 2.61), both regions with full NETS coverage. This result can be explained both by the high number of birth centers that are currently active in these regions (67 in Campania and 44 in Lazio) and by the number of maternity wards carrying out $\leq 500$ births per year (20 in Campania and 12 in Lazio, i.e., 29.9 and 27.3\%, of birth centers, respectively). In 2014, in Italy, $25.2 \%$ of birth centers had an activity of less than 500 births per year, this data increases to $35.7 \%$ if we consider only the five regions without NETS coverage (Table 1).

The results of this survey also showed that most NETS (59.1\%) carried out fewer than 100 transports per year (Fig. 1, panel b), which is a relatively low degree of activity when trying to provide its personnel with an adequate level of skills and experience and good cost performance [20].

Moreover, half of the level III perinatal centers did not have a specially equipped ambulance for neonatal transport (23/21, dedicated/non-dedicated), thus leading to difficulties in providing adequate transport of these 


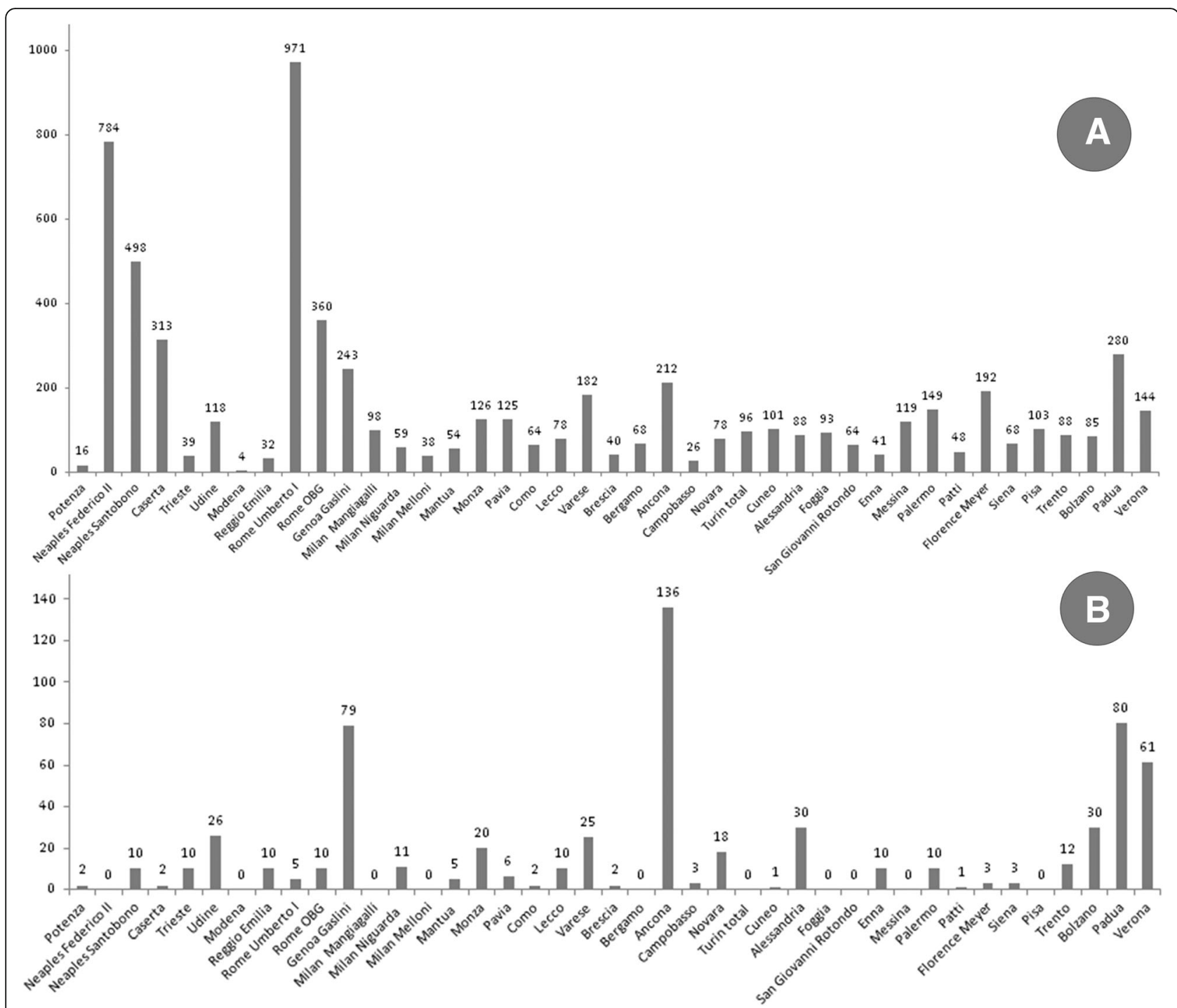

Fig. 2 Distribution of transports in Italy. Total number of transports within various Italian NETS in 2014; note that the four Turin NETS were grouped. Panel a: total number of transports. Panel $\mathbf{b}$ : total number back-transports

vulnerable patients. Non-dedicated ambulances are usually not equipped with dedicated infant incubators, therefore, neonatal transport is usually carried out by simply placing an infant incubator on a stretcher designed for transporting adults [21-23]. It is well known that a lack of adequate equipment and low skill levels of the personnel involved in the transport increases the risk of serious adverse events in the transport of severely ill newborns [6]. Dedicated mechanical neonatal respirators, resuscitation equipments, standard vital-sign monitors, as well asdedicated twin-newborn [24, 25] and iNO [26] devices and are nowadays available and can improve safety and quality of care during transport.

The use of protocols, quality evaluation procedures and training and education programmes became widely adopted among NETS, with the exception of regular audits, which were not performed in $20 \%$ of NETS.

This survey demonstrated that there is no agreement regarding the limits to be applied to age and weight for neonatal transport, i.e., if the transport must be limited to the first 30 days of life, or if a broader approach is possible. We report that as much as $10 \mathrm{~kg}$ of weight or 1 year of age was the upper limits of transported patients, thus changing neonatal transport into pediatric transport.

This study has however some limitations that have to be pointed out. Collection and analysis of survey data have been laborious and required a considerable amount of time. NETS status is very recently changed in some Italian Regions. Abruzzo, Umbria and Calabria have activated their on-call NETS. Meanwhile for Sardegna NETS 
activations is foreseen soon, having already obtained deliberations from their regional governments [8]. The reported missing data together with the recent changes of NETS presence in some regions could represent several of the possible avenues for future researches.

\section{Conclusion}

The inter-facility transport of severely ill and premature newborns is commonly performed in Italy by organized, generally well-equipped and well-trained NETS. The implementation of NETS, together with programs of regionalization of perinatal care have likely played a major role in reducing the neonatal mortality rate that has been observed in Italy in the last two decades (from $5.2 \%$ in 1998 to $3.4 \%$ in 2014). However, NETS coverage is still lacking in many densely populated areas and, where it is present, most of the NETS seem to have a volume of activity that is not sufficient to provide the personnel with an adequate level of skills and an appropriate cost-efficiency ratio. Moreover, many NETS report that, mainly due to financial constraints, there is still a lack of vehicles which are fully dedicated to neonatal transport, that would be of help to improve safety and quality of services.

Differences found in neonatal mortality rates, NTI, NETS availability, and NETS costs among regions seems to reflect the presence of different regional perinatal systems of organizations related to the autonomy of regional governments to legislate in matter of healthcare. It is envisaged that the full application of the State-Regions Conference agreement, along with the implementation of minimal standards of care and education programs driven by the national scientific societies, would lead toward the harmonization of perinatal care in Italy. These measures, however, constitute only a part of the continuing efforts required to improve outcomes and reduce the regional differences in the availability and quality of perinatal services. Periodical national and local audits are needed to evaluate and drive these quality improvement processes.

\footnotetext{
Abbreviations

GA: Gestational Age; ISTAT: Italian National Statistical Institute; NETS: Neonatal Emergency Transport Services; NICU: Neonatal Intensive Care Unit; NTI: Neonatal Transport Index; OECD: Organisation for Economic Cooperation and Development; SD: Standard deviation; SIN: Italian Society of Neonatology; VLBW: Very low birth weight
}

\section{Acknowledgements}

Thanks are due to all the NETS Directors who filled in the survey questionnaire; the following list refers to the name of the director and hospital. S. Schettini (H. San Carlo, Potenza), F. Raimondi (H. Federico II, Naples), M. Carpentieri (H. Santobono, Naples), M. Panico (H. San Sebastiano, Caserta), S. Demarini (H. Burlo Garofalo, Trieste), L. Cattarossi (H. Santa Maria della Misericordia, Udine), F. Ferrari (H. Modena, Modena), G. Gargano (H. Santa Maria Nuova, Reggio Emilia), M. Gente (Policlinico Umberto I, Rome), A. Dotta (H. Bambino Gesù, Rome), C. Bellini (Gaslini Institute, Genoa), F. Mosca (H. Cà Granda Policlinico, Milan), S. Martinelli (H. Niguarda, Milan), E.P. Villani (H. Carlo Poma, Mantua), L. Bernardo
(H. Macedonio Melloni, Milan), P. Tagliabue (H. San Gerarado, Monza), M. Stronati (Policlinico San Matteo, Pavia), M. Barbarini (H. Sant'Anna, Como), R. Bellù (H. Lecco, Lecco), M. Agosti (H. Varese, Varese), G. Chirico (Spedali Civili Brescia, Brescia), G. Mangili (H. Papa Giovanni XXIII, Bergamo), C. Flumini (H. Riuniti Ancona, Ancona), V. Santillo (H. Cardarelli, Campobasso), F. Ferrero (H. Maggiore della Carità, Novara), D. Farina, M. Vivalda, and E. Bertino (H. Sant'Anna, Turin), G. Guala (H. Maria Vittoria, Turin), A. Marra (H. Moncalieri, Moncalieri, Turin), P. Gancia (H. Croce e Carle, Cuneo), D. Gazzolo (H. Arrigo, Alessandria), R. Magaldi (H. Riuniti Foggia, Foggia), A. Gatta and M. Bisceglia ( $H$. Casa Sollievo e Sofferenza, San Giovanni Rotondo, Foggia), F. Tumminelli (ASL4, Enna), I. Barbieri and A. Arco (H. Martino, Messina), G. Sulliotti (H. Cervello, Palermo), C. Cacace (H. Barone Romeo, Patti, Messina), M. Moroni (H. Meyer, Florence), B. Tomassini (H. Santa Maria alle Scotte, Siena), A. Boldrini and P. Biver (H. Pisa, Pisa), H. Messner (H. Bolzano, Bolzano), E. Baraldi and D. Trevisanuto (H. Padova, Padua), and E.M. Padovani (Policlinico Rossi, Verona).

\section{Funding}

None.

Availability of data and materials

The datasets used and/or analyzed during the current study data are available from the Neonatal Transport Study Group of the Italian Society of Neonatology (SIN) on reasonable request.

Some preliminary limited data of this survey have been already partially published in: Gente M, Fedeli T. STEN. I risultati della Survey nazionale SIN. SIN INFORMA - Magazine della Società Italiana di Neonatologia. 2016; 32:1-2. (access to this newsletter is restricted to SIN members only); Bellini C, Gente M. STEN in Italia, situazione Attuale. In: "Organizzazione del sistema di trasporto di Emergenza neonatale (STEN): raccomandazioni del gruppo di studio di trasporto neonatale, Società Italiana di neonatologia." Società Italiana di neonatologia 2018 (access to this recommendations is restricted to SIN members only); Daussac A, Leslie A, Roth-Kleiner M, Zwissig M, Aufieri R, Gente M, Jourdain G. Le transfert néonatal par un SMUR pédiatrique, de la salle de naissance à la réanimation, en France ... et ailleurs. Neonatal Transfer by a Retrieval Team, from the Delivery Room to the NICU, in France ... and Abroad. Rev. Méd. Périnat. 2018;10,50-8 (in this paper have been reported only limited national activity data needed for comparison of Neonatal Transport System activity with other European nations).

\section{Authors' contributions}

All authors read and approved the final manuscript; all authors are accountable for all aspects of the work in ensuring that questions related to the accuracy or integrity of any part of the work are appropriately investigated and resolved. MG (Gente): organized and performed the survey; is responsible for conceiving the study and writing the article; is a former secretary of the Neonatal Transport Study Group, SIN. RA (Aufieri): organized and performed the survey; is responsible for conceiving the study and reviewing the article. RA (Agostino): organized and performed the survey; is responsible for conceiving the study and reviewing the article; is a former secretary of the Neonatal Transport Study Group, SIN. TF (Fedeli): organized and performed the survey; is responsible for conceiving the study. MGC (Calevo): wrote the statistical analysis plan, cleaned and analyzed the data. PM (Massirio): reviewed the article. CB (Bellini): organized and performed the survey; is responsible for conceiving the study and writing the article; is presently the secretary of the Neonatal Transport Study Group, SIN.

Ethics approval and consent to participate Not applicable.

Consent for publication Not applicable.

\section{Competing interests}

The authors declare that they have no competing interests.

\section{Publisher's Note}

Springer Nature remains neutral with regard to jurisdictional claims in published maps and institutional affiliations. 


\section{Author details}

1Department of Pediatrics and Infant Neuropsychiatry, Neonatal Emergency Transport Service, Sapienza University of Rome, Rome, Italy. ${ }^{2}$ Division of Neonatology and Neonatal Intensive Care Unit, ASL Roma 2 - Ospedale Sant'Eugenio, Rome, Italy. ${ }^{3}$ Division of Neonatology, Villa Margherita Private Nursing Home, Rome, Italy. ${ }^{4}$ Neonatal Intensive Care Unit, Fondazione MBBM, Monza, Italy. ${ }^{5}$ Department of Epidemiology, Biostatistics and Committees, IRCCS Istituto Giannina Gaslini, Genoa, Italy. ${ }^{6}$ Neonatal Intensive Care Unit, Neonatal Emergency Transport Service, Department Mother\&Child, IRCCS Istituto Giannina Gaslini, Largo G. Gaslini, 5, 16147 Genoa, Italy.

Received: 14 December 2018 Accepted: 29 March 2019 Published online: 18 April 2019

\section{References}

1. Arora P, Bajaj M, Natarajan G, Arora NP, Kalra VK, Zidan M, et al. Impact of interhospital transport on the physiologic status of very low-birth-weight infants. Am J Perinatol. 2014;31:237-44.

2. Kollèe LA, Brand R, Schreuder A, Ens-Dokkum MH, Veen S, VerlooveVanhorick SP. Five-year outcome of preterm and very low birth weight infants: a comparison between maternal and neonatal transport. Obstet Gynecol. 1992;80:635-8.

3. Finnstrom $O$, Otterblad Olausson P, Sedin G, Serenius F, Svenningsen $N$, Thiringer K, et al. The Swedish national prospective study on extremely low birth weigth (ELBW) infants. Incidence, mortality, and survival in relation to level of care. Acta Paediatr. 1997;86:503-11.

4. Lim MT, Ratnavel N. A prospective review of adverse events during interhospital transfers of neonates by a dedicated neonatal transfer service. Pediatr Crit Care Med. 2008;9:289-93.

5. Agostino R, Aufieri R, Gente M. Neonatal Transport Services. In: Buonocore G, Bracci R, Weindling M, editors. Neonatology. A Practical Approach to Neonatal Diseases. Springer International Publishing Switzerland. Milano: Spriger- Verlag Italia S.r.l.; 2016.

6. Whyte HE, Jefferies AL. Canadian Paediatric society, fetus and newborn committee. The interfacility transport of critically ill newborns. Paediatr Child Health. 2015;20:265-75.

7. Zeitlin J, Papiernik E, Bréart G, EUROPET group. Regionalization of perinatal care in Europe. Semin Neonatol. 2004;9:99-110.

8. Bellini C, Gente M. STEN in Italia, situazione Attuale. In: Organizzazione del sistema di trasporto di Emergenza neonatale (STEN): raccomandazioni del gruppo di studio di trasporto neonatale, Società Italiana di Neonatologia. Società Italiana di Neonatologia; 2018.

9. OECD. OECD reviews of health care quality: Italy 2014: raising standards. Paris: OECD Publishing; 2015.

10. ECD/European Observatory on Health Systems and Policies (2017), Italy: Country Health Profile 2017, State of Health in the EU, Paris: OECD Publishing/Brussels: European Observatory on Health Systems and Policies.

11. Italian Ministry of Health. Attuazione delle azioni previste dall'accordo del 16 dicembre 2010. Linee di indirizzo per la promozione e miglioramento della qualità, della sicurezza e dell'appropriatezza degli interventi assistenziali nel percorso nascita e per la riduzione del taglio cesareo. Monitoraggio al 31 dicembre 2014. 2015. http://www.salute.gov.tt/imgs/C_17_pagineAree_ 4483_listaFile_itemName_3_file.pdf. Accessed 6 Mar 2019.

12. Regione Lazio. Le nascite nel Lazio, Anno 2014. 2015. https://www.regione. lazio.it/binary/rl_sanita/tbl_contenuti/rapporto_nati2014_definitivo.pdf. Accessed 6 Mar 2019.

13. Sistema di sorveglianza della natalità in Campania. Rapporto sula natalità in Campania 2014. 2016. https://www.epicentro.iss.it/percorso-nascita/pdf/ RAPPORTO\%20NATALITA\%202014.pdf. Accessed 6 Mar 2019.

14. Caverni V, Rastrelli M, Aufieri R, Agostino R. Can dedicated ambulances improve the efficiency of the neonatal emergency transport service? J Matern Fetal Neonatal Med. 2004;15:126-8.

15. Italian Ministry of Health. Linee di indirizzo sull'organizzazione del Sistema di Trasporto Materno Assistito (STAM) e del Sistema in Emergenza del Neonato (STEN), 2015. http://www.salute.gov.tt/imgs/C_17_pagineAree_ 4483_listaFile_itemName_4_file.pdf. Accessed 11 Dec 2018.

16. Bellini C, Ramenghi LA. The neonatal transport index could be used as a reference tool for the Italian perinatal care regionalisation plan. Acta Paediatr. 2018;107:902.
17. Leslie A, Stephenson T. Neonatal transfers by advanced neonatal nurse practitioners and paediatric registrars. Arch Dis Child Fetal Neonatal Ed. 2003;88:F509-12.

18. Branger B, Chaperon J, Meurard A. Hospital transfer of newborn infants in the Loire-Atlantic area (France). Rev Epidemiol Santé Publique. 1994;42: 3017-314.

19. Neto MT. Perinatal care in Portugal: effects of 15 years of a regionalized system. Acta Paediatr. 2006;95:1349-52.

20. Bellini C, Pasquarella M, Ramenghi LA, Ambrosino D, Sciomachen AF. Evaluation of neonatal transport in a European country shows that regional provision is not cost-effective or sustainable and needs to be re-organised. Acta Paediatr. 2018;107:57-62.

21. Bouchut JC, Van Lancker E, Chritin V, Gueugniaud PY. Physical stressors during neonatal transport: helicopter compared with ground ambulance. Air Med J. 2011:30:134-9.

22. Karlsson BM, Lindkvist M, Lindkvist M, Karlsson M, Lundström R, Håkansson S. Sound and vibration: effects on infants' heart rate and heart rate variability during neonatal transport. Acta Paediatr. 2012;101:148-54.

23. Bellini C, Risso FM, Sannia A, Campone F, Traggiai C, Ramenghi LA. A retrospective analysis of the occurrence of accidents during 20 years of neonatal transport in Liguria region, Italy. Eur J Emerg Med. 2017;24:71-5.

24. Bellini C, Risso FM, Serveli S, Natalizia AR, Ramenghi LA. Simultaneous transport of twin newborns. Air Med J. 2013;32:334-7.

25. Bellini C, Risso FM, Sannia A, Ramenghi LA. Solving the problem of the transport of twin newborns. Air Med J. 2015;34:5-6.

26. Bellini C, Ramenghi LA. A customized iNO therapy device for use in neonatal emergency transport. Pediatr Neonatol. 2018:5:91-3.
Ready to submit your research? Choose BMC and benefit from:

- fast, convenient online submission

- thorough peer review by experienced researchers in your field

- rapid publication on acceptance

- support for research data, including large and complex data types

- gold Open Access which fosters wider collaboration and increased citations

- maximum visibility for your research: over $100 \mathrm{M}$ website views per year

At $\mathrm{BMC}$, research is always in progress.

Learn more biomedcentral.com/submissions 